\title{
Штраф в системе наказаний за преступмения против собственности и некоторые проблемы повышения его эффективности
}

\author{
и. В. АЗАРОВА
}

Воронежский институт МВД России, г. Воронеж, Российская Федерация

ORCID: https://orcid. org/0000-0003-3497-2126, e-mail.ru: aziravlad@rambler.ru

\section{и. в. ДвоРянСКОв}

Научно-исследовательский институт ФСИН России, г. Москва, Российская Федерация

ORCID: https://orcid. org/0000-0003-0542-5254, e-mail.ru: diw@yandex.ru

Ре ферат. В статье анализируются место и роль штрафа в системе уголовных наказаний, тенденции его установления законодателем и применения судами. Исследуются проблемы охраны собственности, которые всегда находились и остаются в поле зрения законодателя и правовой науки, не теряя своей актуальности, так как относятся к сфере незыблемых жизненно важных интересов личности, общества и государства.

В рамках разработки заявленной темы предпринята попытка разъяснения авторской позиции по трем базовым понятиям: штраф, собственность и эффективность наказания. Формулируется вывод о том, что собственность нужно рассматривать, в том числе при установлении составов преступлений, как сложное многогранное явление, связанное с обеспечением состояния защищенности личности, общества и государства от различных по характеру угроз, в том числе нематериального характера. Подробно исследована в аспекте законодательной регламентации и практики применения наказание в виде штрафа и такая мера уголовно-правового характера, как судебный штраф.

На примере уголовного законодательства Республики Беларусь осуществлен компаративный анализ норм об охране собственности и применения за посягательства на нее наказания в виде штрафа.

В результате авторы приходят к выводу об усилении значимости штрафа в структуре уголовных наказаний, обращают внимание на тенденцию к расширению применения судебного штрафа, освобождающего от уголовного наказания. При этом указывается, что такой подход правоприменителя не вполне соотносится с законодательно установленным принципом социальной справедливости как цели наказания.

Преступления против собственности должны рассматриваться как угроза не только имуществу, но и жизни и здоровью людей (ст. 162 УК РФ), моральным, духовно-нравственным и иным ценностям личности и государственно образованного общества. Такими представлениями, по мнению авторов, следует руководствоваться как в законодательной, так и в правоприменительной практике, в том числе при назначении и исполнении судебного штрафа.

Ключевые слова: собственность; штраф; судебный штраф; цели наказаний; эффективность наказаний.

12.00.08 - Уголовное право и криминология; уголовно-исполнительное право.

Для цитирования: Азарова И. В., Дворянсков И. В. Штраф в системе наказаний за преступления против собственности и некоторые проблемы повышения его эффективности. Пенитенциарная наука. 2020, т. 14, № 4 (52), с. 473-479. DOI 10.46741/2686-9764-2020-14-4-473-479. 


\title{
Fine in the System of Punishments for Crimes against Property and Some Issues Related to the Enhancement of Its Effectiveness
}

\author{
IRINA V. AZAROVA \\ Voronezh Institute of the Ministry of Internal Affairs of the Russian Federation,
} Voronezh, Russian Federation

ORCID: https://orcid. org/0000-0003-3497-2126, e-mail: aziravlad@rambler.ru

\section{IVAN V. DVORYANSKOV}

Research Institute of the Federal Penitentiary Service of Russia, Moscow, Russian Federation

ORCID: https://orcid. org/0000-0003-0542-5254, e-mail: diw@yandex.ru

\begin{abstract}
The article analyzes the place and role of fines in the system of criminal penalties and looks intosome trends in its establishing by the legislator and application by the court. We investigate property protection issues that have always been in the focus of attention of legislators and legal science and that have never lost their relevance, because they relate to the inviolable vital interests of an individual, society and the state. In the framework of the topic under consideration, we undertake to explain our viewpoint on three basic terms: "fine", "property" and "punishment effectiveness". We conclude that property should be considered (among other things in the establishment ofthe elements of a crime) as a complex multifaceted phenomenon associated with ensuring the security of individuals, society and the state from various threats, including those of an intangible nature. We analyze fine as a penalty and fine imposed by the court as a criminal law measure in the aspect of legal regulation and application practice.We carry out comparative analysis of the rules on the protection of property and the application of penalties in the form of a fine for encroachment upon it on the example of the criminal legislation of the Republic of Belarus. As a result, we conclude that the importance of fine in the structure of penal sanctions is increasing; we note that there is a trend to increase the use of a court imposed fine as an exemption from penal sanctions. At the same time,we point outthat this approach used bylegal professionals does not fully fit in with the legally established principle of social justice as the goal of punishment.Crimes against property should be considered as a threat not only to property, but also to the life and health of people (Article 162 of the Criminal Code of the Russian Federation), moral, spiritual and other values of an individual and society. We believe this approach should be used both in legislative and law enforcement practice, including cases of applying a court imposed fine.

Key words: property; fine; court imposed fine; punishment goals; punishment
\end{abstract} effectiveness.

12.00.08 - Criminal law and criminology; penal law.

For citation: Azarova I.V., Dvoryanskov I.V. Fine in the system of punishments for crimes against property and some issues related to the enhancement of its effectiveness. Penitentiary Science, 2020, vol. 14 (52), no. 4, pp. 473-479 . DOI 10.46741/2686-97642020-14-4-473-479.

Проблемы охраны собственности всегда находились и находятся в поле зрения законодателя и правовой науки, не теряя своей актуальности, ибо относятся к сфере незыблемых жизненно важных интересов личности, общества и государства. Их значимость признает и законодатель, закрепляя в основах конституционного строя положение о том, что в нашей стране признаются и равным образом защищаются частная, государственная, муниципальная и иные формы собственности (ст. 8 Конституции Российской Федерации). При этом в ч. 3 ст. 35 Основного закона утверждается, что никто «не может быть лишен своего имущества иначе как по решению суда». Принудительное же отчуждение имущества допускается только при условии предварительного и равноценного его возмещения.

Охрана собственности осуществляется разными способами, включая и уголовноправовые средства [9, с. 118-138]. Извест- 
но, что традиционно в структуре уголовной преступности доминируют хищения [4, с. 461]. Достаточно сказать, что в 2019 г., согласно официальным данным Генеральной прокуратуры Российской Федерации, они составили 42,5 \% от общего количества всех зарегистрированных преступлений. Доля осужденных за преступления, предусмотренные гл. 21 УК РФ, в 2019 г. достигла 37,4 \% [7]. Показатели же судебного штрафа по анализируемой главе оказались еще выше: из 33329 таких штрафов 46,3 \% наложены по статьям данной части уголовного закона.

Вместе с тем научная разработанность темы штрафа и уровень обобщения практики его применения в контексте эффективности данного вида наказания не соответствуют его значимости.

Рассмотрение заявленного вопроса предполагает прежде всего уяснение авторской позиции по трем базовым понятиям: штраф, собственность и эффективность наказания, дискуссия относительно которых не прекращается в правовой науке.

Известно, что термин «штраф» немецкого происхождения - от слова «die Strafe», что в переводе на русский язык означает «наказание» [11, с. 521]. В действующем законодательстве он используется очень широко во множестве отраслей частного и публичного права.

Так, в ст. 330 ГК РФ штрафом (пеней) признается определенная законом или договором денежная сумма, которую должник обязан уплатить кредитору в случае неисполнения или ненадлежащего исполнения обязательства.

В ст. 3.5 КоАП РФ штрафом называется денежное взыскание, выраженное в рублях или в величине, кратной различным показателям, в том числе величине, кратной стоимости предмета административного правонарушения или сумме неуплаченных или подлежащих уплате налогов и пр.

В ст. 46 УК РФ под штрафом понимается денежное взыскание, назначаемое в пределах, предусмотренных уголовным законом.

Анализ легального и доктринального толкования данного феномена позволяет сделать вывод о том, что штраф - это мера материального воздействия на правонарушителя для возмещения причиненного материального ущерба, морального вреда, а также реализации многогранных социально значимых целей наказания.

Что же касается собственности, то она является в своей основе категорией гражданско-правовой, сущность ее выражается в возможности любого лица иметь на законном основании неограниченное количество имущества, свободно владеть, пользоваться и распоряжаться им. Использование данного понятия в других отраслях права является предметом непрекращающихся споров.

Так, существует мнение о том, что состояние и российского уголовного законодательства, и сложившейся уголовно-правовой теории в части, касающейся связи собственности с сущностью уголовного права, является неудовлетворительным [2, с. 4]. Признавая некоторую не совсем обоснованную категоричность данного утверждения, хотелось бы заметить, что в конце прошлого столетия на основе анализа произошедших в стране глобальных изменений социально-экономического и политического характера в уголовно-правовой науке сложилась позиция, согласно которой не всегда имеют решающее значение в определении собственности как объекта посягательства такие признаки, как материальность, экономическая ценность, стоимость. Сам автор приведенного выше умозаключения указывает, что в различных главах УК РФ есть составы, представляющие собственность и как личную сферу (п. «б» ч. 2, п. «а» ч. 3 ст. 58), и как основу социального бытия (ст. 167, 168, 214), и т. п.

Вместе с тем мы разделяем вывод о том, что собственность нужно рассматривать, в том числе при установлении составов преступлений, как сложное многогранное явление [1, с. 22], связанное с обеспечением состояния защищенности личности, общества и государства как основных объектов безопасности от различных по характеру угроз, в том числе нематериального характера [10, с. 313].

За посягательства на собственность в качестве основных и дополнительных применяются восемь видов наказаний из 13 предусмотренных УК РФ. Штраф может выступать как основным, так и дополнительным наказанием.

В УК РБ, с которой наша страна объединена в союзное государство (и мы вправе предположить, что в рамках признаваемого нами интегративного правопонимания [3, с. 57-63] будет происходить «выравнивание» законодательства, регулирующего различные сферы государственной и общественной жизни), количество и виды наказаний за посягательства на собственность совпадают с закрепленными в УК РФ примерно на 70 \%. При этом в УК РБ нет такого наказания, как принудительные работы. Следует сказать, что данная санкция применяется как альтернатива лишению свободы в прямо 
предусмотренных в УК РФ случаях и предполагает привлечение осужденного к труду в местах, определяемых учреждениями и органами уголовно-исполнительной системы, и удержание у него в доход государства от 5 до 20 \% заработной платы. Данный вид наказания в нашей стране был введен Федеральным законом от 07.12. 2011 № 420-Ф3 и реализуется только с 01.01.2017, не пользуясь особой популярностью у правоприменителя. Так, в 2018 г. такая санкция была назначена 1030 лицам, причем это почти в два раза больше, чем в 2017 г.

В отличие от белорусского уголовного закона, в УК РФ нет такого наказания, как общественные работы. Санкция ст. 49 УК РБ предусматривает выполнение осужденным бесплатного труда на срок от 60 до 240 часов в пользу общества, вид занятости определяется органами, ведающими применением общественных работ.

Кроме того, среди особенностей УК РБ в рассматриваемой нами области следует назвать более широкое, чем в России, использование такого наказания, как лишение права занимать определенные должности или заниматься определенной деятельностью, за посягательства на собственность. Представляется, что и в нашей стране с учетом уровня коррупции, признанной Президентом Российской Федерации Д. В. Медведевым в рамках послания Федеральному Собранию в 2008 г. врагом номер один для свободного, демократического и справедливого общества, уместно во всех составах, где должностные лица могут быть причастны к совершению хищений, предусмотреть указанный вид уголовного наказания в качестве альтернативы, в том числе и штрафу.

Наше отношение к многообразию и сочетанию различных видов наказаний скорее позитивное, так как это дает правоприменителю возможность учета особенностей составов преступлений, личности преступника, а также доктринального и легального достижения целей наказания, обеспечения его социальной эффективности [8]. В данном контексте штраф представляет собой в УК РФ особый вид наказания, используемый в различных вариантах: как основной вид наказания, дополнительный вид наказания, иная мера уголовно-правового характера (судебный штраф). В целом штраф является третьей по количеству применений за совершение посягательств на собственность мерой наказания после лишения свободы и обязательных работ. Так, в 2019 г. он был назначен в качестве основного 20800 осужденным за преступления против собственности, что составляет примерно 8,9 \% от общего числа осужденных по гл. 21 УК РФ (228 953).

Законом штраф устанавливается в определенных размерах, указываемых в конкретных составах уголовных преступлений (ст. 46 УК РФ). При этом нижний его предел определен в пять тысяч рублей, верхний в пять миллионов рублей. Параллельно с определением штрафа в абсолютных суммарных величинах он исчисляется: а) в размере заработной платы или иного дохода осужденного за период от двух недель до пяти лет; б) величине, кратной стоимости предмета или сумме различного по характеру коммерческого подкупа; в) величине взятки или суммы незаконно перемещенных денежных средств и (или) стоимости денежных инструментов.

Из установленных сумм минимальных и максимальных величин штрафа в УК РФ делается исключение для штрафа, связанного с коммерческим подкупом, подкупом работника контрактной службы, контрактного управляющего, члена комиссии по осуществлению закупок и иных уполномоченных лиц, представляющих интересы заказчика в сфере закупок товаров, работ, услуг для обеспечения государственных или муниципальных нужд. Наказание в виде штрафа при совершении указанных преступлений минимально не может быть менее двадцати пяти тысяч рублей, максимально - более пятисот миллионов рублей.

При этом законодатель обязывает суд при назначении наказания учитывать тяжесть совершенного преступления и имущественное положение как осужденного, так и его семьи. Подлежат выяснению также возможности получения им заработной платы или иного дохода. Принимая во внимание те же обстоятельства, суд может назначить штраф с рассрочкой выплаты определенными частями на срок до пяти лет.

В случае злостного уклонения от уплаты штрафа, назначенного в качестве основного наказания, он заменяется любым другим наказанием из перечня, содержащегося в УК РФ, кроме лишения свободы. Исключение из данного правила составляет штраф, исчисляемый исходя из величины, кратной стоимости предмета или сумме коммерческого подкупа или взятки, который заменяется наказанием в пределах санкции, предусмотренной соответствующей статьей Особенной части УК РФ. При этом назначенное наказание не может быть условным.

Штраф в качестве дополнительного вида наказания может назначаться только в случаях, предусмотренных соответствующими 
статьями Особенной части УК РФ. Анализ гл. 21 УК РФ показывает, что в тех случаях, когда штраф не является основным видом наказания, он устанавливается в качестве дополнительного (ст. 161-164).

Судебный штраф в качестве разновидности освобождения от уголовной ответственности за совершенное впервые преступление небольшой или средней тяжести введен в гл. 11 УК РФ в 2016 г. федеральным законом № 323-Ф3. Основанием для принятия судом соответствующего решения является возмещение виновным ущерба или заглаживание иным образом причиненного преступлением вреда. Динамика применения судебного штрафа в последние два года характеризуется следующими показателями. В 2019 г. освобождено от уголовной ответственности по ст. 76.2 УК РФ 26040 чел., что на 10588 чел., или $41 \%$, больше, чем в 2018 г. При этом подавляющее большинство освобождений по таким основаниям в 2019 г. (12 850 чел.) приходится на ч. 2 и 3 ст. 158 УК РФ, характеризующиеся наличием отягчающих обстоятельств. Практикуется и освобождение от уголовной ответственности за открытое хищение чужого имущества (ч. 1 ст. 161): в 2019 г. таких случаев зарегистрировано 829. В целом законодатель последние пять лет активно расширял условия и основания освобождения от уголовной ответственности. Так, за указанный период в ст. 76.1 «Освобождение от уголовной ответственности в связи с возмещением ущерба» были внесены дополнения и изменения восемью федеральными законами. Правоприменительная практика отреагировала на эти новации значительным и все возрастающим количеством уголовных дел, прекращаемых по основаниям возмещения убытков или заглаживания причиненного преступлением вреда (освобождение от уголовной ответственности). Так, по данным Судебного департамента при Верховном Суде Российской Федерации, число прекращенных дел, не включая освобождение от уголовного преследования из-за отсутствия состава или события противоправного деяния, составило в 2019 г. 90 911, или 39,7 \% от общего количества осуждений за посягательства на собственность, что существенно больше, чем в 2018 г. (76 474). Ощутимой является и разница в соотношении освобожденных от уголовной ответственности и общего количества осужденных за анализируемый период времени 39,7 и 30,9 \%, причем это на фоне сокращения общего количества осужденных в 2019 г. в сравнении с 2018 г. (с 249231 до 228 953) [6].
Рассмотренные явления в области применения наказаний и освобождения от уголовной ответственности объективно порождают вопрос о социальной эффективности уголовно-принудительной политики государства, в том числе в области охраны собственности, понимаемой как действенность, сводящаяся к способности воздействовать на что-либо [5, с. 914]. В рамках нашего исследования действенность означает достижение целей уголовного наказания в целом и штрафа в частности.

Легальное определение целей наказания содержится в ст. 43 УК РФ. К таковым отнесены восстановление социальной справедливости, исправление осужденного и предупреждение совершения новых преступлений. Если положения анализируемой статьи об исправлении осужденного и предупреждении преступлений носят в целом определенный характер, то относительно социальной справедливости как цели наказания определенность отсутствует. В число спорных вопросов в этой области общественных отношений, на наш взгляд, следует включить установленные законодателем условия освобождения от уголовной ответственности лиц, совершивших преступления, в том числе против собственности. Так, для человека, имеющего денежные средства, дающие возможность возместить причиненный материальный ущерб и иной вред, ответственность практически сводится лишь к лишению этих средств. Тем же, кто не имеет таких средств для освобождения от уголовной ответственности, грозят отбывание реального уголовного наказания, включая лишение свободы, и иные негативные последствия, связанные с судимостью. Весьма спорным положением, противоречащим принципу виновной ответственности, является ч. 2 ст. 88 УК РФ, гласящая, что «штраф, назначенный несовершеннолетнему осужденному, по решению суда может взыскиваться с его родителей или иных законных представителей с их согласия. Штраф назначается в размере от одной тысячи до пятидесяти тысяч рублей или в размере заработной платы или иного дохода несовершеннолетнего осужденного за период от двух недель до шести месяцев».

Таким образом, проведенное исследование дает возможность сделать следующие обобщающие выводы.

Значение штрафа в системе уголовных наказаний, особенно по всем преступлениям против собственности, имеет тенден- 
цию к существенному возрастанию. В значительной мере это относится к судебным штрафам, дающим возможность освобождения от уголовной ответственности, в том числе за совершение преступлений с отягчающими обстоятельствами (ч. 2 и 3 ст. 158 УК РФ).

Преступления против собственности должны рассматриваться как угроза не только имуществу, но и жизни и здоровью людей (ст. 162 УК РФ), моральным, духовнонравственным и иным ценностям личности и государственно образованного общества. Данным подходом, на наш взгляд, следует руководствоваться как в законодательной, так и в правоприменительной практике, в том числе при назначении судебного штрафа.

Проблемы эффективности уголовных наказаний, включая штрафные санкции, многогранны. К ним следует отнести кроме реализации целей наказания и создание непротиворечивого, эффективно действующего правового поля, в том числе в области уголовной политики, и воспитание на этой основе законопослушных граждан, и обеспечение неотвратимости наказания за совершение любого правонарушения, и достижение высокого уровня профессионализма и ответственности лиц, занимающихся реализацией охранительных норм, и многое другое.

\section{СПИСОК ЛИТЕРАТУРЫ}

1. Безверхов, А. Г. Имущественные преступления : автореферат диссертации на соискание ученой степени доктора юридических наук / Безверхов Артур Геннадьевич. - Ижевск, 2002. - 42 с.

2. Бочкарев, С. А. Уголовно-правовая охрана собственности: теоретико-инструментальный анализ : автореферат диссертации на соискание ученой степени кандидата юридических наук / Бочкарев Сергей Александрович. Москва, 2010. - 26 с.

3. Ершов, В. В. Правовое и индивидуальное регулирование общественных отношений : монография / В. В. Ершов. - Москва : РГУП, 2018. - 627 с. - ISBN 978-5-93916-631-7.

4. Лунеев, В. В. Преступность XX века: мировые, региональные и российские тенденции / В. В. Лунеев. - Москва: Волтерс Клувер, 2005. - 912 с. - ISBN 5-466-00098-1.

5. Ожегов, С. И. Толковый словарь русского языка : 80000 слов и фразеологических выражений / С. И. Ожегов и Н. Ю. Шведова. - Москва : Азбуковник, 1999. - 944 с. - ISBN 5-89285-003-X.

6. Отчет о числе осужденных по всем составам УК РФ за 2018 и 2019 гг. - URL: http://www.cdep.ru/index. php?id=79\&item=5259 (дата обращения: 12.04. 2020).

7. Состояние преступности в России за январь - октябрь 2018 г. - URL: https://genproc.gov.ru/upload/iblock/ddb/ sbornik 10 2018.pdf (дата обращения: 12.04. 2020).

8. Хатуаев, В. У. Проблемы эффективности наказаний в трудах советских ученых второй половины XX века / В. У. Хатуаев, Е. С. Шаимова // Судебная власть и формы ее реализации в России : сборник материалов Всероссийской научно-практической конференции. - Воронеж : Истоки : Центр. фил. Рос. акад. правосудия, 2011. C. 133-141. - ISBN 978-5-88242-901-9.

9. Черников, В. В. Современная государственная система охраны собственности в России / Черников В. В. Москва : Инфра-М, 1995. - 224 с. - ISBN 5862250964.

10. Шульга, А. В. Объект и предмет преступлений против собственности в условиях рыночных отношений и информационного общества : монография / А. В. Шульга. - Москва : Юрлитинформ, 2007. - 376 с. - ISBN 978-593295-346-4.

11. Юридический энциклопедический словарь / под общей редакцией А. Я. Сухарева. - Москва : Советская энциклопедия, 1987. - 528 с.

\section{REFERENCES}

1. Bezverkhov A.G.Imushchestvennye prestupleniya: avtoreferat dissertatsii na soiskanie uchenoi stepeni doktora yuridicheskikh nauk [Property crimes: Doctor of Sciences (Law) dissertation abstract]. Izhevsk, 2002. 42 p.

2. Bochkarev S.A. Ugolovno-pravovaya okhrana sobstvennosti: teoretiko-instrumental'nyi analiz: avtoreferat dissertatsii na soiskanie uchenoi stepeni kandidata yuridicheskikh nauk [Criminal-legal protection of property: theoretical and instrumental analysis: Candidate of Sciences (Law) dissertation abstract]. Moscow, 2010. 26 p.

3. Ershov V.V. Pravovoe i individual'noe regulirovanie obshchestvennykh otnoshenii: monografiya [Legal and individual regulation of public relations: monograph]. Moscow: RGUP, 2018. 627 p.

4. Luneev V.V. Prestupnost' XX veka: mirovye, regional'nye i rossiiskie tendentsii [Crime of the twentieth century: world, regional and Russian trends]. Moscow: Volters Kluver, 2005. 912 p.

5. Ozhegov S.I., ShvedovaN.Yu.Tolkovyi slovar' russkogo yazyka: 80000 slov i frazeologicheskikh vyrazhenii [Explanatory dictionary of the Russian language: 80,000 words and phraseological expressions]. Moscow: Azbukovnik, 1999.944 p.

6. Otchet o chisle osuzhdennykh po vsem sostavam UK RF za 2018 i $2019 \mathrm{gg}$. [Report on the number of convicts under all parts of the Criminal Code of the Russian Federation for 2018 and 2019]. Available at: http://www.cdep.ru/index. php?id=79\&item=5259 (accessed April 12, 2020).

7. Sostoyanie prestupnosti v Rossii za yanvar' - oktyabr' 2018 g. [Crime situation in Russia in January-October 2018] Available at: https://genproc.gov.ru/upload/iblock/ddb/sbornik_10_2018.pdf (accessed April 12, 2020).

8. Khatuaev V.U., ShaimovaE.S.Problems of the effectiveness of punishments in the works of Soviet scientists of the second half of the 20th century. In: Sudebnaya vlast' i formy ee realizatsii v Rossii: sbornik materialov Vserossiiskoi nauchnoprakticheskoi konferentsii [Judicial power and forms of its implementation in Russia: proceedings of an all-Russian scientific and practical conference]. Voronezh: Istoki: Tsentr. fil. Ros. akad. pravosudiya, 2011. Pp. 133-141. (In Russ.).

9. Chernikov V.V. Sovremennaya gosudarstvennaya sistema okhrany sobstvennosti v Rossii [Modern state system of property protection in Russia]. Moscow: Infra-M, 1995. 224 p.

10. Shul'ga A.V. Ob»ekt i predmet prestuplenii protiv sobstvennosti v usloviyakh rynochnykh otnoshenii i informatsionnogo obshchestva: monografiya [Object and subject of crimes against property in the conditions of market relations and information society: monograph]. Moscow: Yurlitinform, 2007. 376 p.

11. SukharevA.Ya. (Ed.). Yuridicheskii entsiklopedicheskii slovar' [Encyclopedic dictionary of law]. Moscow: Sovetskaya entsiklopediya, $1987.528 \mathrm{p}$. 


\section{CВЕДЕНИЯ ОБ АВТОРАХ / INFORMATION ABOUT THE AUTHORS}

ИРИНА ВЛАДИМИРОВНА АЗАРОВА - старшИЙ преподаватель кафедры гражданско-правовых и экономических дисциплин Воронежского института МВД России, г. Воронеж, Российская Федерация. ORCID: https://orcid. org/0000-0003-3497-2126, e-mail.ru: aziravlad@rambler.ru ИВАН ВЛАДИМИРОВИЧ ДВОРЯНСКОВ - докТор юри-

дических наук, профессор, главный научный сотрудник Научно-исследовательского института ФСИН России г. Москва, Российская Федерация. ORCID: https://orcid. org/0000-0003-0542-5254, e-mail.ru: diw@yandex.ru

IRINA V. AZAROVA - Senior Lecturer of the Department of Civil Law and Economic Disciplines, Voronezh Institute of the Ministry of Internal Affairs of the Russian Federation, Voronezh, Russian Federation. ORCID: https://orcid org/0000-0003-3497-2126, e-mail.ru: aziravlad@rambler.ru IVAN V. DVORYANSKOV - Chief Researcher, Doctor of Sciences (Law), Professor, Research Institute of the Federal Penitentiary Service of Russia, Moscow, Russian Federation. ORCID: https://orcid. org/0000-0003-05425254, e-mail.ru: diw@yandex.ru 